\title{
GESTÃO AMBIENTAL COMPARTILHADA: O PROGRAMA MUNICÍPIO VERDE AZUL
}

Nome do Autor (a) Principal

Mariana Mazeti de Lima

Nome (s) do Coautor (a) (s)

Luana Ferreira Pires; Joseana Barissa de Oliveira.

Instituição ou Empresa

Universidade Estadual Paulista Júlio de Mesquita Filho - UNESP

E-mail de contato: mari_mazeti@hotmail.com

Palavras-chave

Programa Município Verde Azul. Meio Ambiente. Política Pública.

\section{INTRODUÇÃO}

As políticas públicas, que visam o desenvolvimento da sociedade, surgiram em prol da evolução do capitalismo, sendo que, este ganhou grande importância durante a Revolução Industrial e, logo após esse período, novas perspectivas emergiram por meio de reivindicações sociais com o objetivo de cobrar ações mitigadoras dos impactos negativos das atividades humanas sobre o meio ambiente (BATISTA et al., 2014).

No Brasil, Salheb et al. (2009) cita que o surgimento de políticas públicas ambientais aconteceu durante o governo de Getúlio Vargas, sendo o marco desse acontecimento em 1934 com a criação dos Códigos das Águas, de Minas e Florestal. Essas medidas foram o ponto de partida para o início de novas perspectivas relacionadas aos recursos naturais.

Dessa forma, as políticas públicas ambientais brasileiras tomaram um caminho fortalecedor, com apoios e incentivos governamentais. Outro aspecto 
relacionado a elas é que possuem uma característica atípica, por serem consideradas descentralizadas em suas tomadas de decisões, pois, os estados e municípios ficam responsáveis pela criação de suas próprias políticas públicas ambientais. Essa estratégia visa ampliar a atuação da administração local e participação social, o que proporciona melhorias na eficiência da gestão ambiental (BARBOSA; GOLDEMBERG, 2004).

Seguindo esses objetivos, a Secretaria de Meio Ambiente (SMA) do Estado de São Paulo criou em 2007 o Projeto Município Verde (PMV), juntamente com outros 21 Projetos Ambientais Estratégicos, elaborados para serem conhecidos como certificações ou selos ambientais. O PMV, no entanto, recebeu a palavra "azul" em seu nome depois de alguns anos, pois, posteriormente foi percebido a importância da gestão hídrica municipal e, em 2011 consolidou-se como programa pela SMA, adotando novas abordagens das temáticas ambientais e tornando-se 0 Programa Município Verde e Azul (PMVA) (KONRAD, 2014; GIRÃO, 2012).

O número de municípios que são certificados pelo programa teve um aumento significativo desde sua criação, em seu primeiro ranking no ano de 2008 contava com 44 municípios certificados, sendo que, em 2014 esse número cresceu para 118, no qual hoje todos os 645 municípios do Estado de São Paulo fazem parte do programa, segundo a página da Secretaria do Meio Ambiente.

\section{OBJETIVOS}

\subsection{OBJETIVO GERAL}

Caracterizar o Programa Município Verde Azul, política pública do Estado de São Paulo.

\subsection{OBJETIVOS ESPECÍFICOS}

- Descrever as etapas que constituem o processo ciclíco anual do Programa Município Verde Azul.

- Identificar quais são as Diretivas Ambientais propostas pelo Programa Município Verde Azul.

- Apresentar o método utilizado para o cálculo do Índice de Avaliação Ambiental e as suas variáveis. 


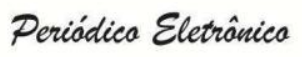

\section{METODOLOGIA}

Este estudo teve como metodologia a pesquisa de caráter bibliográfico e documental em fontes secundárias a fim de recolher informações sobre o Programa Município Verde Azul e as formas de avaliar os municípios que aderiram ao programa. Do mesmo modo, foram coletados dados disponíveis na página da Secretaria do Meio Ambiente do Governo do Estado de São Paulo.

Por meio da pesquisa foram identificadas dez Diretivas Ambientais do programa, sendo elas: Esgoto Tratado, Resíduos Sólidos, Biodiversidade, Arborização Urbana, Educação Ambiental, Cidade Sustentável, Gestão das Águas, Qualidade do Ar, Estrutura Ambiental e Conselho Ambiental. A cada diretiva são atribuídos critérios que são calculados pelo Índice de Avaliação Ambiental (IAA) e, então, rankeados pelo Programa.

O diagnóstico dos dados ocorreu de forma qualitativa, uma vez que este estudo visou identificar as diretivas do PMVA e seus critérios de avaliação. Nessa abordagem o processo é mais valorizado que o resultado, pois a intenção é identificar as circunstâncias que levam aos fatos, de forma que a interpretação do pesquisador dos fenômenos (comportamento, contexto social, ações e outros) acerca do objeto de estudo é uma característica relevante (MENGA; ANDRÉ, 1986).

\section{RESULTADOS}

Criado em 2007 pela Secretaria de Meio Ambiente (SMA) do Estado de São Paulo, e consolidado sob o nome de Programa Município Verde Azul em 2011, essa política pública tem por objetivo alcançar eficiência na gestão ambiental incentivando e instruindo as prefeituras do estado a fim de que seja elaborada e executada uma Agenda Ambiental Estratégica (SMA, 2015).

A adesão à política é voluntária, sua formalização exige a assinatura do Termo de Adesão pelo prefeito do município acompanhada do testemunho de um vereador e um cidadão. Em seguida, são nomeados dentre os funcionários do quadro da prefeitura, um Interlocutor e seu Suplente, os quais representarão a prefeitura e intermediarão a comunicação entre ela e a SMA (GIRÃO, 2012). 
Os municípios são avaliados anualmente por meio do Relatório de Gestão Ambiental preenchido no Sistema Informatizado do Programa pelo Interlocutor. Esse relatório contempla o diagnóstico do município, os objetivos estabelecidos para o ano e as estratégias utilizadas para alcança-los, conforme indicado na Resolução no 26, de 28 de abril de 2015.

As estratégias devem atender à 10 diretivas estabelecidas pelo programa, conforme indicadas no Quadro 1.

Quadro 1: As Diretivas e as suas Características Fundamentais.

\begin{tabular}{|l|l|}
\hline \multicolumn{1}{|c|}{ DIRETIVAS } & \multicolumn{1}{c|}{ CARACTERISTICAS FUNDAMENTAIS } \\
\hline 1. Esgoto Tratado & $\begin{array}{l}\text { Ampliar os índices de coleta, transporte, tratamento e disposição, de forma } \\
\text { adequada, dos esgotos urbanos }\end{array}$ \\
\hline $\begin{array}{l}\text { 2. Resíduos } \\
\text { Sólidos }\end{array}$ & $\begin{array}{l}\text { Fortalecer a festão dos resíduos sólidos domiciliares e da construção civil, de } \\
\text { programas ou ações de coleta seletiva e da responsabilidade pós-consumo }\end{array}$ \\
\hline 3. Biodiversidade & Proteger e/ou recuperar áreas estratégias para a manutenção da biota \\
\hline $\begin{array}{l}\text { 4. Arborização } \\
\text { Urbana }\end{array}$ & $\begin{array}{l}\text { Incrementar a gestão do meio ambiente urbano por meio do planejamento e } \\
\text { definição de prioridades para a arborização urbana }\end{array}$ \\
\hline $\begin{array}{l}\text { 5. Educação } \\
\text { Ambiental }\end{array}$ & $\begin{array}{l}\text { Implementar a Educação Ambiental no âmbito formal e informal em três eixos: } \\
\text { formação, capacitação e mobilização da comunidade }\end{array}$ \\
\hline $\begin{array}{l}\text { 6. Cidade } \\
\text { Sustentável }\end{array}$ & Estimular o uso racional dos recursos naturais \\
\hline $\begin{array}{l}\text { 7. Gestão das } \\
\text { Águas }\end{array}$ & $\begin{array}{l}\text { Fortalecer a gestão municipal sobre a qualidade da água para abastecimento } \\
\text { público }\end{array}$ \\
\hline $\begin{array}{l}\text { 8. Qualidade do } \\
\text { Ar }\end{array}$ & $\begin{array}{l}\text { Implementar atividades e participar de iniciativas que contribuam para a } \\
\text { manutenção ou melhoria da qualidade do ar e do controle da emissão excedente } \\
\text { e gases de efeito estufa }\end{array}$ \\
\hline $\begin{array}{l}\text { 9. Estrutura } \\
\text { Ambiental }\end{array}$ & $\begin{array}{l}\text { Estimular o fortalecimento das Secretarias / Departamento / Diretorias de Meio } \\
\text { Ambiente }\end{array}$ \\
\hline $\begin{array}{l}\text { 10. Conselho } \\
\text { Ambiental }\end{array}$ & Estimular o funcionamento regular do Conselhos Municipais de Meio Ambiente \\
\hline
\end{tabular}

Fonte: SÃO PAULO, 2013.

Para cada uma dessas diretivas a SMA elenca anualmente Indicadores de Desempenho, critérios que deverão ser atendidos pelas estratégias adotadas pelo município aos quais são atribuídos pontos que constituem o cálculo do Índice de Avaliação Ambiental (IAA), parâmetro adotado para mensurar a satisfação das diretivas. Com essa finalidade, aplica-se a fórmula: IAA = $\Sigma$ IDi $-P P$

As variáveis da equação são:

$\Sigma I D i$ - Pode atingir pontuação máxima de 100. Corresponde ao somatório dos Indicadores de Desempenho (IDi) das Diretivas Ambientais, que variam de 0 a 10 e sofrem adequação segundo o peso da diretiva a qual representam.

PP - Pode atingir pontuação máxima de 30. Corresponde aos passivos e/ou pendências municipais, relacionados a despesas ambientais não liquidadas e deveres referentes aos aterros sanitários e coleta e tratamento de esgoto. 


\section{Periódica Eletrânica \\ Fórum Ambiental}

da Alta Paulista
Volume 11, Número 07, 2015

Politicas Públicas e a Proteção do Meio Ambiente

Segundo Girão (2012), a pontuação atribuída aos Indicadores de Desempenho de cada diretiva ocorre mediante a conferência dos documentos digitais, inseridos no Relatório de Gestão Ambiental e entregues, em CD, DVD ou Pen Drive, a Secretaria do PMVA até o encerramento do prazo do Sistema Informatizado. Os arquivos e informações fornecidos são passíveis de auditoria. Essas informações, bem como a forma de preenchimento do Sistema Informatizado, são fornecidas na capacitação anual dos Interlocutores, para orientar a construção do Planejamento Ambiental Municipal.

Ao final do ciclo do programa, os resultados do IAA de todos os municípios signatários são divulgados à SMA, às prefeituras e aos cidadãos. Organizadas, essas pontuações formam o Ranking Ambiental, sendo que os melhores colocados concorrem às premiações: Prêmio Anual aos Interlocutores, Prêmio Governador André Franco Montoro e Interlocutores, e Prêmio Parceria Verde Azul (SMA, 2015).

Ademais, a Resolução №26, de 28 de abril de 2015, traz que os municípios que atingirem pontuação acima de $0 \mathrm{em}$ todas as diretivas, atenderem aos critérios das Diretivas Esgoto Tratado e Resíduos Sólidos, possuírem o Conselho Municipal de Meio Ambiente e implementarem a Estrutura Executiva Ambiental, e alcançarem pontuação igual ou superior a 80 no IAA, são certificados pelo Programa Município Verde Azul. Essa certificação confere garantia de competência na adoção de ações a fim de atender as diretivas do programa.

\section{CONCLUSÃO}

O Programa Município Verde Azul foi consolidado em 2011, promovendo a gestão ambiental estadual por meio de diretivas estipuladas pelo mesmo e, atendidas pelos municípios que aderem à política. À vista disso, os critérios de avaliação de cada diretiva proposta pelo PMVA servem para rankear os municípios participantes, com o intuito de incentivar a preservação ambiental presente no Estado de São Paulo.

O município que adere ao PMVA estimula a população a preservar o meio ambiente em que vive por meio de ações socioambientais que desenvolve para ser avaliado pelo programa. Desta forma a gestão ambiental municipal é fortalecida, o que favorece a qualidade de vida da população e da cidade. 


\section{REFERÊNCIAS}

BARBOSA, L. M.; GOLDEMBERG, J. A legislação ambiental no Brasil e em São Paulo. Revista Eco 21, Ano XIV, Edição 96, Novembro 2004. Disponível em:<http://www.eco21.com.br/textos/textos.asp?|D=954 >. Acesso em: 10 Abr. 2015.

BATISTA, A.C. et al. Descrição do programa município verde azul no município de Quadra - SP. Revista Perspectiva em Educação, Gestão \& Tecnologia, 2014, Vol.3, № 6. p. 01-11.

GOVERNO DO ESTADO DE SÃO PAULO - SISTEMA AMBIENTAL PAULISTA. Município Verde Azul. Disponível em: <http://www.ambiente.sp.gov.br/municipioverdeazul/>. Acesso em: 10 Abr. 2015

KONRAD, E. C. G. Políticas de apoio a gestão da arborização urbana: uma análise do Programa Município Verde Azul. 2014. 161 f. Tese (Doutorado em Agronomia)- Universidade Estadual Paulista. Ilha Solteira, 2014.

MENGA, L.; ANDRÉ, M. E. D. A. Pesquisa em educação: abordagens qualitativas. São Paulo: EPU, 1986.

SALHEB, G. J. M. et al. Políticas públicas e meio ambiente: reflexões preliminares. Planeta Amazônia: Revista Internacional de Direito Ambiental e Políticas Públicas, 2009, Vol. 1. № 1. p. 0527.

SÃO PAULO (Estado). Secretaria do Meio Ambiente. PMVA 2013 Manual de instruções. Programa Município Verde Azul. 2013. Disponível em $<$ http://www.ambiente.sp.gov.br/pactodasaguas/files/2011/05/Manual_PMVA_2013_2.pdf>.Acesso em: 01 maio 2015.

SECRETÁRIA DE ESTADO DO MEIO AMBIENTE (São Paulo). Resolução no $\mathbf{2 6}$, de $\mathbf{2 8}$ de abril de 2015. Disponível em:

<http://www.ambiente.sp.gov.br/municipioverdeazul/files/2015/04/Resolu\%C3\%A7\%C3\%A3o-SMA26_2015_PMVA.pdf >. Acesso em: 01 maio 2015.

SÃO PAULO (Estado). Secretária de Estado do Meio Ambiente. Resolução ํㅡ 26, de 28 de abril de 2015. Estabelece procedimentos operacionais e parâmetros de avaliação no âmbito do Programa Município Verde Azul, para o exercício de 2015, e revoga as Resoluções correlatas. Diário Oficial [do] Estado de São Paulo, 29 de abril de 2015. Seção 1, p. 55-59. Disponível em: <http://www.ambiente.sp.gov.br/municipioverdeazul/files/2015/04/Resolu\%C3\%A7\%C3\%A3o-SMA26_2015_PMVA.pdf >. Acesso em: 01 maio 2015.

SECRETARIA DO MEIO AMBIENTE. O programa. Disponível em:<http://www.ambiente.sp.gov.br/municipioverdeazul/o-projeto/>. Acesso em : 9 abr. 2015. 